\title{
Bazı makroalglerin Drosophila melanogaster'in hayatta kalışı üzerine etkileri
}

\section{The effects of some macroalgae on viability of Drosophila melanogaster}

\author{
Şükran Çakır Arıca ${ }^{1 *}$ (D) Sevil Demirci ${ }^{1}$ • Ayşe Özyılmaz ${ }^{1}$ • Selda Öz $\bullet$ Ecem Arslantaş ${ }^{1}$ \\ 1 İskenderun Teknik Üniversitesi, Deniz Bilimleri ve Teknolojisi Fakültesi, İskenderun, Türkiye \\ 2 Kırıkkale Üniversitesi, Fen Edebiyat Fakültesi, Biyoloji Bölümü, Kırıkkale, Türkiye \\ *Corresponding author: sukran.caki@@iste.edu.tr
}

Received date: 22.05 .2017

Accepted date: 31.07 .2017

How to cite this paper:

Çakır Arıca, Ş., Demirci, S., Özyılmaz, A., Öz, S. \& Arslantaş, E. (2017). The effects of some macroalgae on viability of Drosophila melanogaster. Ege Journal of Fisheries and Aquatic Sciences, 34(4):451-454. doi: 10.12714/egejfas.2017.34.4.12

Öz: Bu çalışmanın amacı üç farklı makroalgin (Codium sp., Cystoseira sp., ve Polyides sp.) üzerinde en çok çalışılan ve araştırma yapılan model canlı olan Drosophila melanogaster' in hayatta kalışına etkisinin araştırılmasıdır. Drosophila melanogaster' in niçin çalışııldığının birincil nedeni; bu türün, çok kısa sürede ve hızlı üreme oranına sahip olmasıdır. Diğer laboratuvar hayvanları ile karșılaştıııldıklarında Drosophila melanogaster' in genetik bilgi birikiminin yeterli olmasıdır. Bu nedenle, birçok sentetik ve doğal bileşenin canlının hayatta kalma oranı üzerine etkisi, ökaryotik bir canlı olan Drosophila'da sıklıkla test edilmiş̧ir. Tam metamorfoz geçiren bu canlıya test bileşikleri larva evresinde uygulanır ve döngü tamamlandığında, yetişkin formda etki araştırlır. Bu çalışmada, makroalglerden Codium sp., Cystoseira sp., and Polyides sp., özütleri Instant Drosophila Medium Formula 4-24' e eklenip Drosophila melanogaster'e larval dönemde, üç grupta verilmiş, kontrol grubunda ise su kullanıımıştır. Bu çalışma, makroalglerden Codium sp., Cystoseira sp., and Polyides sp., özütlerinin, Drosophila melanogasterïn hayatta kalışına pozitif etkisini göstermiştir.

Anahtar kelimeler: Makroalg, Codium sp., Cystoseira sp., Polyides sp., Hayatta kalış, Drosophila melanogaster

Abstract: The aim of this study is to investigate the effects of three different macroalgae (Codium sp., Cystoseira sp., and Polyides sp.) on viability of Drosophila melanogaster which is the most widely studied insect species in scientific researches. One of the primary reasons why Drosophila melanogaster is one of so widely studied insect is because of their extremely fast breeding rate in a very short time. Compared to other laboratory animals, the Drosophila melanogaster gene pattern is one of the most widely understood. This may allow some modifications to be made with a very good survival rate. Once these basic functions are completed, the insect hatches and develops into a larval form and stars feeding. At this point, the larvae are feed with what kind of feed want to be tested. In this current study, extracts of macroalgae, Codium sp., Cystoseira sp., and Polyides sp., were added into Instant Drosophila Medium Formula 4-24 and given the Drosophila melanogaster in three groups. There was also a fourth group (control group) which is not added extracts of macroalgae in their feed but water. The results of this study showed that macroalgae, Codium sp., Cystoseira sp., and Polyides sp., had positive effects on viability of Drosophila melanogaster.

Keywords: Macroalgae, Codium sp., Cystoseira sp., Polyides sp., viability, Drosophila melanogaster

\section{Gíriş}

Çok hücreli ökaryotik organizmalardan olan makroalgler, denizlerin önemli canlı kaynaklarından biridir. Ayrıca, birincil üretimin temel prosesi olan fotosentez olayını gerçekleştirdiklerinden dolayı ekolojik açıdan da çok önemli gruptadırlar. Dolayısıyla dengeli bir ekosistem için en önemli yapıtaşlarından biridir (Wilson, 2002).

Bu canlılar zengin biyokimyasal içerikleri nedeniyle gıda, tıp, tarım, hayvancilık ve endüstriyel alanlarda hammadde kaynağı olarak kullanılmaktadır (Ak, 2015). Denizel makroalgal hammaddeler, enerji ve çevre sorunlarının üstesinden gelmek için tercih edilen bir yöntem olarak artan bir öneme sahiptir (Baghel v.d., 2017). Ayrıca, yaşlanma karşıtı olarak dermatolojik tedavide, etken madde kaynağı olarak bir potansiyel olarak görülmektedir (Wang vd., 2017; Figueiredo vd., 2016). Ayrıca stres kaynaklı metabolik sendromlarda algal bioaktif bileşiklerin terapik yönü son yıllarda önem kazanmıştır (Freile-Pelegrin ve Robledo, 2014). Özellikle kıyılarımızda doğal yayılış alanına sahip olan Cystoseira cinsine ait türler hayvan gübre ve gıda işletmeciliğinde protein kaynağı olarak kullanılmaktadır (Çetingül vd., 1996). Yapısal polisakkarit ve lignin seviyelerine bağlı olarak, Sıvı biyoyakıt üretiminde cazip besin stokları arasındadır. Makroalgler su ortamında yetiştirilebildiğinden, kara kaynaklı bitkilerle dolayısıyla insan gıdalarıyla rekabet halinde değillerdir. Bu yüzden önemli çevresel avantajlara da sahiptir (Mohseni vd., 2016).

Dünya genelinde, 291 makroalg türü kullanılmaktadır. Bu 
makroalgler ekonomik olarak yaklaşık 6 milyar dolar değerinde ürün pazarı oluşturmaktadır. Hem yetiştiricilik hem de doğadan toplama yoluyla 28 milyon ton üretim yapılmaktadır (McHugh, 2003; Ak, 2015) Akdeniz sahillerinde ise Chlorophyta üyelerine ait 82 , Phaeophyta üyelerine ait 85 , Rhodophyta üyelerine ait 228 takson dağlım göstermektedir (Özvarol, 2009). Algler hücre içinde biriktirdikleri pigment, protein, karbonhidrat, yağ, vitamin ve mineral maddeler nedeniyle birçok canlı grubu için esansiyaldirler. Bu maddeler; farmasötik ve nutrasötik olarak metabolitler ismi ile anılırlar (Becker, 2007).

Algler aynı zamanda yüksek protein ve yağ içerikleri ile biyoteknoloji çalışmalarında aranan değerli kültür organizmalarıdır. Yetiştiricilik için elverişli olmalarını sağlayan yüksek adaptasyon yeteneği gibi pek çok özelliğe de sahiptirler (Taşkın ve Öztürk, 2005; Wells vd, 2017).

Alglerin özellikle endüstriyel amaçlı kullanımları mikro ve makroalgler düzeyinde farklııklar göstermektedir. Mikroalglerin üretiminde (bakteriyel kaynaklarda olduğu gibi) kontaminasyon ve hasat zorluk riski nedeniyle, endüstriyel üretimde hammadde kaynağı olarak daha çok denizel makroalgler (Porphyra, Laminaria, Gracilaria gibi) tercih edilmektedir (Özdemir ve Erkmen, 2013).

Makroalglerin katkı maddesi olarak kullanımı ve hatta tıp alanında kullanımı giderek artmaktadır (Murdinah, 2008). Çünkü, alglerin karbonhidrat, protein, lipid, yağ asitleri, gliserol, doğal pigmentler (beta-karoten, astaksantin, ksantofil, fikobilin) ve amino asitlerce (Durmaz vd., 2002) çok zengin oldukları, ayrıca mineral, vitamin, polisakkaritler (Arasaki ve Arasaki, 1983) ve polifenoller gibi antibakteriyel, antifungal ve antiviral özelliğe sahip biyoaktif maddeler (Chandini vd., 2008; Wang vd., 2017) içerdikleri tespit edilmiş̧ir. Algler antioksidan vitamin ve pigmentlerin yanı sıra çoklu doymamış yağ asitlerinin de zengin bir kaynağıdır (Gökpınar vd., 2001). Ayrıca uygun biyolojik özelliklerinden dolayı manuple edilebilirliği de oldukça yüksektir. Bu nedenle, model organizmalar olarak sıklıkla kullanılmaktadırlar (Creed vd.1998, Prathep 2003). Bu da yaşlanma ve ömür uzunluğu gibi çalışmalarda (Sarıkaya vd. 2006; Peleg vd., 2016) temel etken madde olarak kullanılmaları imkanını ortaya koymaktadır.

Drosophila melanogaster genotoksisite (Çakır ve Sarıkaya, 2005; Öz ve Çakır Arıca, 2016), yaşlanma ve ömür uzunluğu çalışmaları (Çakır ve Bozcuk, 2000; Sarıkaya vd., 2006), çeşitli hastalıkların moleküler mekanizmalarının araştırıması (Laurent vd., 2013; Broughton vd., 2008; Zhang vd., 2013) gibi çeşitli araştırmalarda da kullanılan bir organizmadır. Ökaryotik bir canlı olan Drosophila melanogaster ve memelilerdeki biyolojik, fizyolojik ve nörolojik özelliklerin birçoğu benzerlik göstermektedir (Pandey ve Nichols, 2011).

Bu çalışma, farklı türlerden oluşan algal özütün, Drosophila' nın embriyonel gelişim ve hayatta kalışına etkisinin tespiti için bir ön çalışma niteliğindedir. Bu çalışmada temel amaç, farklı türlerden oluşan alg özütlerinin Drosophila melanogaster'in hayatta kalışına etkisini araştırmaktır.

\section{MATERYAL VE METOT}

\section{Alg örnekleri}

Konacık ve Kale olmak üzere, denizel biota açısından Doğu Akdeniz'in 2 farklı bölgesinden makroalg örnekleri toplandı. Örnekleme Şubat-Mart aylarında yapıldı. Bu türler, Chlorophyta, Phaeophyta ve Rhodophyta olmak üzere üç familyaya aittir. Ait oldukları familya sırasına göre Codium sp., Cystoseira $s p$. ve Polyides $s p$. olarak cins düzeyinde adlandırıldı (Şekil 1).
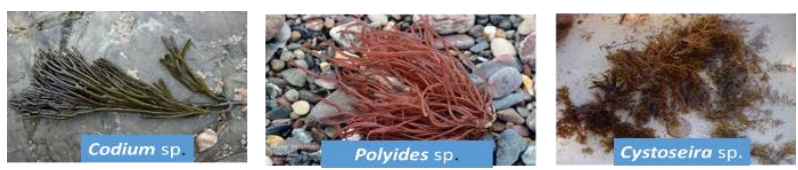

Şekil 1. Araştırma için örneklenen Codium sp., Cystoseira sp. ve Polyides sp. fotoğrafları (Anonim)

Figure 1. The sampled photographs of Codium sp., Cystoseira sp. ve Polyides sp. in the study

\section{Alg ekstraktlarının hazırlanması}

Dalma ve elle toplama yöntemiyle elde edilen algler, deniz suyu ile yıkanarak epifitler, sedimentler ve diğer organik maddelerden temizlendi. Örneklenen algler, polietilen poşetler içinde laboratuara taşınıp, tuz ve kirliliğin giderilmesi için musluk suyu ile tekrar yıkandı (Sivasankari, 2006). Yıkama işleminden sonra örnekler $0.5 \mathrm{~cm}$ ile $1 \mathrm{~cm}$ boyutunda parçalama işlemine tabi tutuldu. Daha sonra $40^{\circ} \mathrm{C}^{\prime}$ lik etüvde 2 hafta süre ile kurutulan örnekler porselen havanda öğütüldü. Her bir örnekten $20 \mathrm{gr} \mathrm{tartllarak,} \mathrm{üzerine} 200 \mathrm{ml}$ etanol eklendi ve yatay çalkalayıcıda (125 rpm), oda sıcaklığında 24 saat süreyle ekstraksiyona tabi tutuldu. Süre sonunda ekstraksiyon filtre edildikten sonra, evaporatör araciıı̆ıyla etanol uzaklaştıııld. Elde edilen özütler, denemelerde kullanılıncaya kadar $+4^{\circ} \mathrm{C}$ 'de amber rengi şişelerde muhafaza edildi.

\section{Uygulama ve değerlendirme}

Hayatta kalış çalışmalarında Drosophila melanogaster'in doğal ırkı olan, oregon, kullanıldı. Drosophila stok kültürleri $\% 40-\% 60$ bağıl nem, $25 \pm 1^{\circ} \mathrm{C}$ sıcaklık ile sürekli karanlık koşullarını taşıyan etüvde, hazır Drosophila ortamı (Instant Drosophila Medium Formula 4-24, Carolina Biological Supply Cooperation, Burlington, NC, USA) içeren şişelerde yaşatıldı. Oregon ırkına ait stoklar boşaltıldıktan sonra ortalama 4 saat içinde virgin (çiftleşmemiş) dişileri toplandı. 1-3 günlük dişi ve erkek bireylerin çaprazlanmasından ortalama $72 \pm 1$ saat sonra larva toplama işlemi yapıldı. Larvalar besi ortamından musluk suyu ile yıkanarak ayrıldı. Her uygulamada 1,5 gr hazır Drosophila ortamı $5 \mathrm{ml}$ test solüsyonu ile ıslatıldı ve 100 larva ortama eklendi (Graf vd, 1989). Alg özütleri $1,5 \mathrm{mg} / 5 \mathrm{ml}$ dozunda uygulandı, kontrol grubunda sadece distile su kullanıldı. Her bir örnek ve kontrol grubu için 3 tekrarlı uygulama yapıldı. Test maddeleri içeren ortama gömülen larvalar gelişimlerini tamamlamaya bırakıldı. Her uygulama grubu için pupadan çıkan bireyler eterle bayıltılarak cinsiyetlerine göre ayrıldı, toplam dişi ve erkek birey sayısı kaydedildi (Çakır ve Sarıkaya, 2004). Elde edilen sayısal sonuçlar MS Excel ile grafikte sunuldu. 


\section{BULGULAR VE TARTIŞMA}

Codium sp., Cystoseira sp. ve Polyides sp. özütlerinin

Drosophila melanogaster larvalarının hayatta kalışları üzerine etkileri Şekil 2'de sunulmaktadır. Test edilen üç alg özütüntün her biri kontrol grubuna göre larvaların hayatta kalış oranlarını pozitif yönde etkilemiştir.

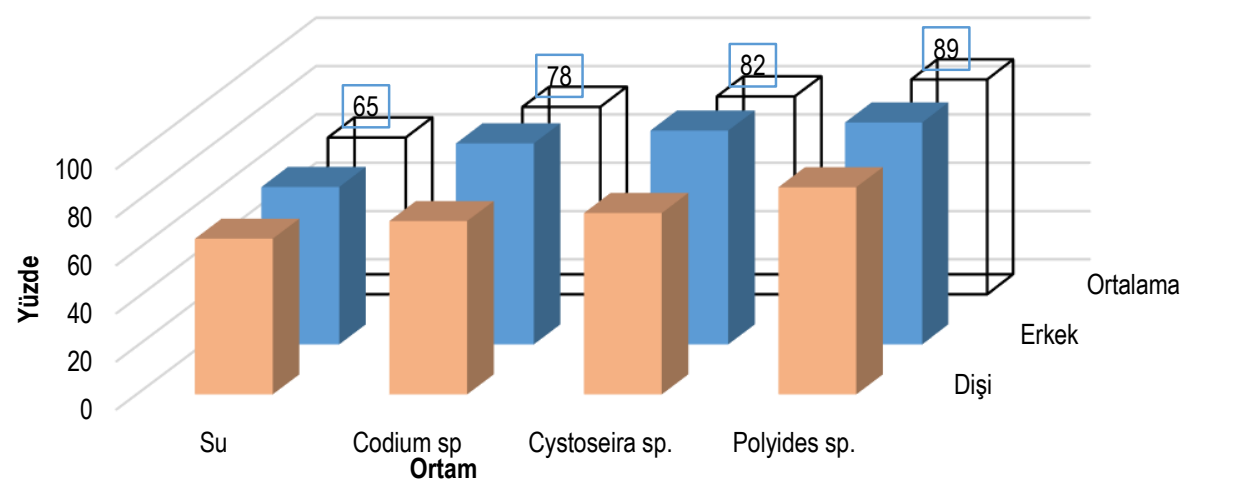

Şekil 2. Dişi, Erkek ve Toplam Drosophila melanogaster bireylerinin farklı alg ortamlarda hayatta kalma oranları

Figure 2. The survival rates of Drosophila melanogaster by female, male, and total number in the different algae environments

Su kontrol grubunda hayatta kalış oranları hem dişi hem de erkek bireyler için $\% 65$ olarak bulunmuştur. Test edilen her 3 alg grubu içinde hem dişi hem de erkek bireylerde hayatta kalış oranı su kontrol grubuna göre bir artış göstermiştir. Kontrol dâhil tüm gruplarda hayatta kalış oranı erkek bireylerde dişilere nazaran daha yüksek bulunmuştur. Bu durum, böceklerin metabolik hızının, dış faktörlerden olan besin şartlarılya değişmesine bağlanabilir (Lanciani vd., 1991; Macedo vd., 2003). Özellikle erkek bireylerdeki artışta, Drosophila'nın populasyon yoğunluğu, besin miktarı ve çeşidi gibi etkenlerde önemli rol oynamaktadır (Koç ve Gülel 2006).

Alg gruplarının su kontrole göre hayatta kalış oranlarındaki artışa bakıldığında Codium sp. en az artış gösterirken (\%78), Polyides sp. (\%89) en fazla artı̧ gösteren grup olarak değerlendirilmiştir. $\mathrm{Bu}$ artışın nedeni, diğer türlerden farklı olarak bu grubun floridae nişastası depo etme özelliğinden kaynaklandığı düşünülmektedir. Polyides sp. Florideophyceae sınıfına ait bir tür olduğundan bu sınıfın üyelerinin hem floridae nişastasını depo etme özellikleri hem de hücrelerin birleşim

\section{KAYNAKÇA}

Ak, İ. (2015). Sucul ortamın ekonomik bitkileri; makro algler. Dünya Gıda Dergisi. Aralık Sayısı: 88-97.

Arasaki, S. \& Arasaki, T. (1983). Vegetables from the sea. Japanese Publishing Industry Japan Publ. Inc., Tokyo, 96:251-223.

Baghel, R.S., Mantri, V.A. \& Reddy, C.R.K. (2017). A New Wave of Research Interest in Marine Macroalgae for Chemicals and Fuels: Challenges and Potentials. Fuels, Chemicals and Materials from the Oceans and Aquatic Sources, 43-63. doi: 10.1002/9781119117193.ch3

Becker, E.W. (2007). Micro-algae as a source of protein. Biotechnology Advances, 25(2): 207-210. doi: 10.1016/j.biotechadv.2006.11.002

Broughton, S., Alic, N., Slack, C., Bass, T., Ikeya, T., Vinti, G. \& Partridge, L. (2008). Reduction of DILP2 in Drosophila triages a metabolic phenotype from lifespan revealing redundancy and compensation among DILPs. PloS one, 3(11), e3721. doi: 10.1371/journal.pone.0003721 yerlerinde proteinsi kapak bulundurdukları bildirilmektedir (Çakı, 2009). Çünkü floridae nişastasının yüksek yapılı bitkilerde bulunan nişasta ile benzer biyokimyasal özellikleri taşıdığı bildirilmektedir (Viola, 2001). Bu durumun Polyides sp. grubundaki hayatta kalış oranını olumlu etkilemiştir.

Algler flavonoid ve karotenoid gibi zengin antioksidan özellikteki içerikleri nedeniyle çevre kirliliğinin artığı günümüzde alternatif besin kaynağı ve etken madde potansiyeli olma açısından da önem kazanmıştır. Modern yaşamın getirdiği olumsuz etkilerin hücreler bazında oluşturduğu hasarların antioksidan besin katkıları ile tölere edilerek günümüzde erken yaşlanmaya neden olan metabolizmal hastalıkların azaltılabileceği fikri kabul görmektedir. Bu bağlamda alglerin hayatta kalma, hücredeki serbest radikallerin etkisiz hale getirilmesi ve anti kanser etkileri gibi potansiyellerinin araştıııması benzeri çalışmalar, sucul kaynakların değerlendirile bilirliğini arttırmak ve alternatif tıp arayışları açısından önemlidir.

Chandini, S.K., Ganesan, P. \& Bhaskar, N. (2008). In vitro antioxidant activities of three selected brown seaweeds of India. Food Chemistry, 107(2):707713. doi: 10.1016/j.foodchem.2007.08.081

Creed, J.C., Kain, J.M. \& Norton, T.A. (1998). An Experimental Evaluation of Density and Plant Size in Two Large Brown Seaweeds. J Phycol, 34:3952. doi: 10.1046/j.1529-8817.1998.340039.x

Çakı, Z. (2009). Ege Denizi kıyısında bulunan bazı makro yosun türleri antimikrobiyal ve antioksidan aktiviteleri tanımlamaktadır. Celal Bayar Üniversitesi, Fen Bilimleri Enstitüsü Yüksek Lisans Tezi (pp 119) Manisa, Türkiye.

Çakır, S. \& Bozcuk, A.N. (2000). Longevity in some wild type and hybrid strains of Drosophila melanogaster. Turkish Journal of Biology, 24(2):321-330.

Çakır, Ş. \& Sarıkaya, R. (2005). Genotoxicity testing of some organophosphate insecticides in the Drosophila wing spot test. Food and Chemical Toxicology, 43(3):443-450. doi: 10.1016/j.fct.2004.11.010 
Cetingül, V., Aysel, V. \& Kurumlu, Y. (1996). Cystoseira barbata (Good et Woodw) C.Ag., (Fucales, Fucophyceae)'nin Aminoasit İçeriklerinin Saptanması. Ege Journal of Fisheries and Aquatic Sciences, 13(1-2):119121.

Durmaz, Y., Işık, O., Bandarrra, N.M., Cirik, S., Turan, G. \& Gökpınar, Ş. (2002). Porphyridium cruentum (Rhodophyceae) yağ asitleri kompozisyonuna kurutma yöntemlerinin etkisi. Ege Journal of Fisheries and Aquatic Sciences, 19(1-2):189-195

Figueiredo, F., Encarnação, T. \& Campos, M.G. (2016). Algae as Functional Foods for the Elderly. Food and Nutrition Sciences, 7(12):1122 doi: 10.4236/fns.2016.712107

Freile-Pelegrín, Y. \& Robledo, D. (2014). Bioactive phenolic compounds from algae. Bioactive Compounds from Marine Foods: Plant and Animal Sources, 113-129.

Gökpınar, Ş., Göksan, T. \& Durmaz, Y. (2001). PUFA Kaynağı Olarak Mikroalgler, XI. Ulusal Balıkçılık Bilim Sempozyumu, Hatay, Türkiye: Bildiriler Kitabı.

Graf, S.A. \& Sokolowski, M.B. (1989). Rover/sitter Drosophila melanogaster larval foraging polymorphism as a function of larval development, foodpatch quality, and starvation. Journal of Insect Behavior, 2(3):301-313. doi: 10.1007/BF01068057

Koç, Y. \& Gülel, A. (2006). Fotoperiyot ve Besin Çeşidinin Drosophila melanogaster Meigen, 1830 (Diptera: Drosophiladae) Gelişim Süresi Ömür Uznluğu, Verim ve Eşey Oranına Etkisi. Ondokuz Mayıs Üniversitesi Ziraat Fakültesi Dergisi, 21(2):204-212.

Lanciani, Carmine A., John Anderson F. \& James Giesel. T. (1991). Effect of photoperiod on metabolic rate in a subtropical population of Drosophila melanogaster. Comparative Biochemistry \& Physiology Part A: Physiology 100(2):347-348. doi: 10.1016/0300-9629(91)90480-Z

Laurent, R.S., O'Brien, L.M., \& Ahmad, S.T. (2013). Sodium butyrate improves locomotor impairment and early mortality in a rotenone-induced Drosophila model of Parkinson's disease. Neuroscience, 246: 382-390. doi: 10.1016/j.neuroscience.2013.04.037

Macedo, L.P.M., Souza, B., Carvaiho, C.F. \& Ecole, C.C. (2003). Influence of the Photoperiod on Development and Reproduction of Chrysoperia externa (Neuroptera: Chrysopidae). Neutropical Entomology, 32(1):91-96. doi: 10.1590/S1519-566X2003000100013

McHugh, D.J. (2003), A guide to the Seaweed Industry. Food and Agriculture Organization of the United Nations, Roma, Italya, 103 p.

Mohseni, S., Pishvaee, M.S. \& Sahebi, H. (2016). Robust design and planning of microalgae biomass-to-biodiesel supply chain: A case study in Iran. Energy, 111:736-755. doi: 10.1016/j.energy.2016.06.025

Murdinah, V.D. (2008). Application of Bio Activatörs to Produce Organic Fertilizer From Seaweed Processing Waste. Journal of Applied and Industrial Biotechnology in Tropical Region, Vol. 1 (Special Edition) ISSN:1979 9748
Öz, S. \& Çakır Arıca, Ş. (2016). Evaluation of antigenotoxic effect of Myrtus communis L. (myrtle) fruit extract. International Conference on Natural Science and Engineering (ICNASE'16), March 19-20 2016, Kilis, Türkiye, Oral presentation, Proceeding Book, 2474-2481.

Özdemir, N. \& Erkmen, J. (2013). Yenilebilir Biyoplastik Üretiminde Alglerin Kullanımı. Karadeniz Fen Bilimleri Dergisi, 3(8):89-104.

Özvarol, Y. (2009). Doğu Akdeniz Kıyılarının (Gazipassa- İskenderun) Makrobentik Deniz Florasının. Belirlenmesi. Süleyman Demirel Üniversitesi, Fen Bilimleri Enstitüsü (pp 130) Isparta, Türkiye.

Pandey, U.B. \& Nichols, C.D. (2011). Human disease models in Drosophila melanogaster and the role of the fly in therapeutic drug discovery. Pharmacological reviews, 63(2):411-436. doi: 10.1124/pr.110.003293

Peleg, S., Feller, C., Forne, I., Schiller, E., Sévin, D.C., Schauer, T. \& Nogueira, M.S. (2016). Life span extension by targeting a link between metabolism and histone acetylation in Drosophila. European Molecular Biology Organization reports: $17(3): 455-469$.

Prathep, A., Marrs, R.H. \& Norton, T.A. (2003). Spatial and Temporal Variations in Sediment Accumulation in An Algal Turf and Their Impact on Associated Fauna. Mar Biol 142:381-90. doi: 10.1007/s00227-002-0940-4

Sarıkaya, R., Çakır, Ş. \& Solak, K. (2006). Development of protective agents Drosophila melanogaster'de (mwhxflr) the effect of the length of life (in Turkish). Kastamonu Education Magazine, 14(1):173-184.

Sivasankari, V.D. (2006). Effect of seaweed extracts on the growth and biochemical constituents of Vigna sinensis. Bioresource Technology, 97(14):1745-1751. doi: 10.1016/j.biortech.2005.06.016

Taşkın, E. \& Öztürk, M. (2005). Evaluation of Species in taxonomy of Algae and Brown Turkey (in Turkish). Turkish Journal of Aquatic Life, 3(4):137-144.

Viola, R. Nyvall P. \& Pedersén M. (2001). The unique features of starch metabolism in red algae." Proceedings of the Royal Society of London B: Biological Sciences, 268.1474:1417-1422. doi: 10.1098/rspb.2001.1644

Wang, H.M.D., Li, X.C., Lee, D.J. \& Chang, J.S. (2017). Potential biomedical applications of marine algae. Bioresource Technology, 244(2):1407-1415. doi: 10.1016/j.biortech.2017.05.198

Wells, M.L., Potin, P., Craigie, J.S., Raven, J.A., Merchant, S.S., Helliwell, K.E. \& Brawley, S. H. (2017). Algae as nutritional and functional food sources: revisiting our understanding. Journal of Applied Phycology, 29(2):949-982. doi: 10.1007/s10811-016-0974-5

Wilson, S. 2002. Nutritional Value of Detritus and Algae in Blenny Territories on the Great Barrier Reef. J. of Exp. Mar. Biol. Ecol., 271:155-169. doi: 10.1016/S0022-0981(02)00035-7

Zhang, F., Zhao, Y. \& Han, Z. (2013). An in vivo functional analysis system for renal gene discovery in Drosophila pericardial nephrocytes. Journal of the American Society of Nephrology, 24:1-7. doi: 10.1681/ASN.2012080769 